\title{
Smart Phone Applications as a Source of Information on Stroke
}

\author{
Divyanshu Dubey, ${ }^{\mathrm{a}}$ Amod Amritphale, ${ }^{\mathrm{b}}$ Anshudha Sawhney, ${ }^{\mathrm{c}}$ Nupur Amritphale, ${ }^{\mathrm{d}}$ Pradeep Dubey, \\ Ambarish Pandey ${ }^{a}$ \\ ${ }^{a}$ University of Texas Southwestern Medical Center, Dallas, Texas, USA \\ bUniversity of Nevada School of Medicine, Las Vegas, Nevada, USA \\ 'Netaji Subhash Chandra Bose Medical College, Jabalpur, Madhya Pradesh, India \\ ${ }^{\mathrm{d}}$ Sir Ganga Ram Hospital, New Delhi, India \\ e Devchaya Medical Center, Jabalpur, India
}

Background and Purpose Smartphone applications have been increasingly identified as a novel platform for dissemination of healthcare related information. However, there have been no studies done to evaluate the availability and content of stroke related apps. Purpose: This study aims to identify and analyze stroke-related applications available on the Apple iTunes and Android Google Play Store.

Methods The Apple iTunes store and Android Google Play Store were searched for strokerelated applications on July 27, 2013 using keywords: stroke, brain attack, intracranial hemorrhage, subarachnoid hemorrhage, cerebral infarction. The content of the applications was analyzed by two independent investigators.

Results A total of 93 relevant applications (46.2\% android and 53.8\% iPhone) were identified of which $47.3 \%$ were available free of cost. $92 \%$ of apps were identified as useful by users and over $60 \%$ had scientifically valid information. There is a significant participation of healthcare agencies in dissemination of stroke related information through apps with $47.3 \%$ apps being uploaded by them. Over half of all stroke related apps were aimed towards health care workers (51.6\%), 75\% of which could be utilized as bedside tools for patient care and remainder had information related to recent research advances. The difference in scientific validity between the apps aimed at general population versus healthcare professionals was statistically significant $(P<0.01)$. There was no statistical association between cost of app and scientific validity or usefulness.

Conclusions Smartphone apps are a significant source of information related to stroke. An increasing participation of healthcare agencies should be encouraged to promote dissemination of scientifically valid information.

Keywords Stroke; Mobile applications; Smartphone; Information; Technology
Correspondence: Divyanshu Dubey University of Texas Southwestern Medical Center, 5253 Harry Hines Blvd. Dallas, Texas 75235 , USA

Tel: +1-(214)2839782

E-mail: divyanshudubey87@gmail.com

Received: March 15, 2014

Revised: May 3, 2014

Accepted: May 8, 2014

The authors have no financial conflicts of interest.

\section{Introduction}

The ability of smart phones to deliver directed health information to the patients and healthcare providers is path breaking and has opened up an entirely new era of health communication. As of 2013, more than 50 billion and 48 billion apps have been downloaded from the Apple App Store and Android Play Store respectively by millions of smart phone users all over the 
world. ${ }^{1,2}$

An increasing number of medical professionals are using smart phone applications for accessing clinical information on the internet and as clinical calculators. A prior study had estimated that the percentage of medical professionals using smart phones will rise to $66-90 \%$ by $2012 .{ }^{3}$ Increasing prevalence and popularity of smart phone apps among health- care professionals complements the medical practice and has gained wide acceptance as a training and information tool. ${ }^{4,5}$ Smart phone apps are increasingly being used by the patients for information on early identification of stroke symptoms, risk factor awareness and management. ${ }^{6,7}$

Health-related smart phone apps are being actively studied for potential applications in a wide variety of fields of medical importance including but not limited to dermatology, ${ }^{8}$ ophthalmology ${ }^{9,10}$ and cancer. ${ }^{11}$ Many studies have questioned the validity and specificity of the health care information available on these subjects. ${ }^{12,13}$ The quality of information disseminated in these apps would therefore play an important role in determining the quality of health care provided. The primary aim of our study was to evaluate the stroke related apps available on Apple app store and the Android Play Store and to analyze the content and potential usefulness in the health care delivery system.

\section{Methods}

The Apple iTunes store and Android Google Play Store were searched for stroke-related applications on July 27, 2013. The search terms used to select the apps were: stroke, brain attack, intracranial hemorrhage, subarachnoid hemorrhage, cerebral infarction. The content of the applications was analyzed by two independent investigators (DD, AA). Each app was analyzed and classified on the basis of cost, target audience, type of information, validity, involvement of health-care agencies and usefulness based on audience reviews and ratings.

\section{Costs}

Apps were categorized on the basis of fee/cost of download.

1. Free: Apps which were downloaded free of cost.

2. Paid: Apps which could be downloaded after making a payment.

\section{Target audience}

Apps were categorized based on the people for whom the apps were designed for.

1. Health care workers: these apps included clinical information and recent advances targeted for health care workers to be used in the hospital/clinic/research laboratory.
2. General population: these apps were those which could be utilized by general population for education, primary or secondary prevention and self management of their illnesses.

\section{Type of information}

Apps were divided on the basis of information provided.

1. General information about the disease process: these included the apps providing information about etiology, pathogenesis and categorization of ischemic stroke, intracranial and subarachnoid hemorrhage.

2. Recent research and advances: these apps provided information about latest research and advances in the field of vascular neurology which have impacted the patient management.

3. Tools to be used by health care professionals: these were various apps (e.g. NIHSS, $\mathrm{ABCD}_{2}, \mathrm{CHA}_{2} \mathrm{DS}_{2}$-VASc etc.) used by health care professionals for evaluation and management.

4. Tools to be used by patients: these apps were utilized by the patients for maintaining medication compliance or management of risk factor(s) for stroke prevention.

5. General awareness and support group apps: included information about various awareness programs and support groups for patients and their relatives.

6. Miscellaneous: this included relevant or irrelevant information on stroke which could not be categorized into any of the above categories.

\section{Uploading agencies}

Apps were divided into two groups based on the agency which sold or uploaded the app on Apple iTunes or Google Play Store.

1. Health Care Agencies (HCAs): these included national or international medical/surgical associations, medical universities/medical schools, pharmaceutical companies, hospitals, research associations or medical journals.

2. Non Health Care Agencies (Non HCAs): private or government agencies which do not belong to the above mentioned organizations.

\section{Scientific validity}

The scientific validity was based on the references provided by uploading agency/individual along with application. The apps which didn't have references, validity was decided based on whether or not the information or tool was compatible with updated stroke literature, expert reviews, national guidelines and recommendations by American Stroke Association.

1. Scientifically validated apps: content of these apps was backed by scientific evidence.

2. Non Validated apps: these apps did not contain scientific 
evidence based information.

\section{Usefulness}

It was decided on the basis of audience reviews and ratings.

1. Not useful: apps with poor ratings or comments (e.g. less than 2 stars).

2. Moderately useful: apps which were rated as average by the users (e.g. 2-3 stars).

3. Very useful: apps with good rating and reviews by the users (e.g. more than 3 stars).

\section{Statistical analysis}

Values are expressed as simple proportions. Univariable analysis was performed using Pearson's chi-squared test or Fisher's exact test for categorical variables. A 2-sided $P$ value of $<0.05$ was considered significant. Kappa coefficient of agreement between two investigators was calculated. All statistical analysis was done using IBM SPSS Statistics 19.0 for Windows (SPSS Inc.).

\section{Results}

A total of 107 apps were identified using the search terms. Fourteen apps didn't have information about stroke, therefore excluded from the study. A total of 93 relevant applications were analyzed. Forty three of these apps were uploaded on Google Play Store and fifty on Apple iTunes. Descriptive analysis of information collected in various categories was performed (Table 1).

\section{Costs}

Out of the 93 apps, 47\% (44) were available free of cost. More than half of these free apps (24) were considered very useful by the audience. Whereas 27 of 49 paid apps were considered very useful as per user ratings. $61 \%$ (27) free apps and 57\% (28) paid apps had scientifically valid information. There was no statistical association between cost of app and scientific validity or usefulness. 55\% (24) free apps and 49\% (24) paid apps were targeted for health care professionals.

\section{Target audience}

Over half of all stroke related apps (48) were aimed towards health care workers and 45 were meant to be used by general public. $75 \%$ of apps aimed at health care workers could be utilized as bedside tools for patient care and remainder had information related to recent research advances. More than half (55\%) of the apps for health care workers and $46 \%$ apps for general public were free of cost. Nearly $90 \%$ (43) apps for health care professionals were scientifically valid where as only $27 \%$ (12) targeting general population had the backing of scientific evidence. This difference was found to statistically significant $(P<0.01)$.

\section{Type of information}

Majority of apps provided tools to be used by HCAs (38.3\%) and general public (35.5\%). 4.3\% apps provided general information about stroke etiology, pathogenesis and classification, where as $15.1 \%$ and $4.3 \%$ had information about recent advances in stroke research and support groups respectively. Majority (72\%) tool applications for HCAs were considered very useful by the reviewers. $60 \%$ of tools for non-HCAs were considered moderately useful as per the user ratings. $92 \%$ of tools for HCAs and only $20 \%$ tools for non HCAs tools were backed by scientific literature. There was statistically significant difference between scientific validity of HCAs and non HCAs tool applications $(P<0.05)$.

\section{Uploading agency}

There was a significant participation of healthcare agencies in dissemination of stroke related information with $47.3 \%$ (44) apps being uploaded by them. Remaining $52.7 \%$ (49) apps were uploaded by Non HCAs. 66\% (29) apps uploaded by HCAs were rated very useful and only $11 \%$ (5) considered non useful by the users. 70\% (31) and 49\% (24) apps uploaded by HCAs and non HCAs were considered scientifically valid. The

Table 1. Descriptive analysis of stroke related smart phone applications

\begin{tabular}{|c|c|c|c|c|c|c|c|c|}
\hline & $\begin{array}{c}\text { Type of } \\
\text { information }\end{array}$ & $\begin{array}{c}\text { General } \\
\text { information }\end{array}$ & $\begin{array}{c}\text { Research \& } \\
\text { advances }\end{array}$ & $\begin{array}{c}\text { Tools for health } \\
\text { care agencies (HCA) }\end{array}$ & $\begin{array}{l}\text { Tools for } \\
\text { Non-HCA }\end{array}$ & $\begin{array}{l}\text { Support } \\
\text { groups }\end{array}$ & Miscellaneous & Total \\
\hline Total apps & Number (\%) & $4(4.3)$ & $14(15.1)$ & 36 (38.7) & $33(35.5)$ & $4(4.3)$ & $2(2.2)$ & $93(100)$ \\
\hline \multirow{2}{*}{ Scientifically valid information } & Yes & 3 & 12 & 33 & 7 & 0 & 0 & 55 \\
\hline & No & 1 & 2 & 3 & 26 & 4 & 2 & 38 \\
\hline \multirow[t]{3}{*}{ Usefulness (as per user ratings) } & Very & 2 & 11 & 26 & 11 & 1 & 0 & 51 \\
\hline & Moderate & 1 & 2 & 8 & 21 & 3 & 0 & 35 \\
\hline & Non-useful & 1 & 1 & 2 & 1 & 0 & 2 & 7 \\
\hline \multirow[t]{2}{*}{ Cost of apps } & Free & 3 & 10 & 15 & 10 & 4 & 2 & 44 \\
\hline & Paid & 1 & 4 & 21 & 23 & 0 & 0 & 49 \\
\hline
\end{tabular}


Table 2. Outcome of descriptive analysis of stroke related smart phone apps

\begin{tabular}{|c|c|c|c|c|c|c|c|c|}
\hline & \multirow{2}{*}{$\begin{array}{c}\text { Type of } \\
\text { information }\end{array}$} & \multicolumn{2}{|c|}{ Uploading agency } & \multicolumn{2}{|c|}{ Targeted audience } & \multicolumn{3}{|c|}{ Usefulness of apps (as per user ratings) } \\
\hline & & Health care agency (HCA) & Non-HCA & $\mathrm{HCA}$ & Non-HCA & Very useful & Moderately useful & Non useful \\
\hline Total apps & Number & 44 & 49 & 48 & 45 & 51 & 35 & 9 \\
\hline Scientifically valid information & $\begin{array}{l}\text { Yes } \\
\text { No }\end{array}$ & $\begin{array}{l}31 \\
13\end{array}$ & $\begin{array}{l}24 \\
25\end{array}$ & $\begin{array}{r}43 \\
5\end{array}$ & $\begin{array}{l}12 \\
33\end{array}$ & $\begin{array}{r}42 \\
9\end{array}$ & $\begin{array}{l}11 \\
24\end{array}$ & $\begin{array}{l}2 \\
5\end{array}$ \\
\hline Cost of apps & $\begin{array}{l}\text { Free } \\
\text { Paid }\end{array}$ & $\begin{array}{l}24 \\
20\end{array}$ & $\begin{array}{l}20 \\
29\end{array}$ & $\begin{array}{l}24 \\
24\end{array}$ & $\begin{array}{l}20 \\
25\end{array}$ & $\begin{array}{l}24 \\
27\end{array}$ & $\begin{array}{l}15 \\
20\end{array}$ & $\begin{array}{l}5 \\
2\end{array}$ \\
\hline
\end{tabular}

difference in scientific validity between apps uploaded by HCAs and non HCAs was not statistically significant.

\section{Usefulness}

Majority (55\%) of the apps were rated as very useful by users. $38 \%$ were moderately useful and remaining (7\%) non-useful. 56\% (27 very useful and 20 moderately useful) apps were paid apps. There was no significant difference between cost of the apps and usefulness.

\section{Scientific validity}

Majority of apps (59.1\%) were scientifically valid. Most of these $(78 \%)$ were aimed at healthcare professionals (Table 2). The difference in scientific validity between the apps aimed at general population versus healthcare professionals was statistically significant $(P<0.01) .96 \%(53)$ of the valid apps were considered useful (42 very useful and 11 moderately useful) by the users. Interestingly $87 \%$ (33) of non valid apps were also considered useful (9 very useful and 24 moderately useful).

Kappa Coefficient of agreement between the two investigators $(\mathrm{DD}, \mathrm{AA})$ was 0.97 .

\section{Discussion}

The world is seeing an exponential increase in the use of smart phone applications as a source of valid and updated health-care related information by the general public and health-care professionals. ${ }^{14,15}$ Smart phone applications have been studied as a source of information for different medical specialties. ${ }^{4,5,8-13,16}$ Paucity of scientific accuracy and clinical relevance of majority of apps directed at general users is a growing concern., ${ }^{7,-20}$ Even the applications available to the HCAs are not screened for the quality and validity of information. ${ }^{18-20}$ Our study addresses the nature and volume of information about stroke available to users, both HCAs and non- HCAs, through iPhone apps and Android Play Store. In our study we found that there was no statistical association between cost of app and scientific validity or usefulness.

Nearly 90\% (43) apps targeting health care professionals were scientifically valid where as only $27 \%$ (12) targeting general population had the backing of scientific evidence. There was statistically significant difference between scientific validity of HCAs and non HCAs tool apps further emphasizing the need for a central agency which can screen the sensitive health care related information being made available to the general population.

Although some of the previous studies on utilization of smart phone applications in health care were focused only on Apple iTunes, ${ }^{11}$ our study did a comprehensive review by including both the android Play store and Apple iTunes as our database. A limitation of our study was that we analyzed only English language apps and the apps available in other languages were not included in the study. Tools formed a considerable proportion of the apps for stroke used by health care professional or patients. Due to limited number of apps certain variables could not be analyzed to assess for statistical significance. Since the number of users rating the apps varied, there is a potential risk for selection bias while assessing usefulness of stroke related apps. There were 9 apps that were common among Apple iTunes and Android Play store, these were included separately since these apps would be downloaded and utilized by different users. But analyzing these as separate apps may have affected the results pertaining of type of information and target audience.

The smart phone applications are fast becoming the peg of information to both the health care providers and the general population. There is a huge demand in the society for healthcare information about debilitating and fatal illnesses like stroke and cardiovascular diseases. Information can now be targeted and provided right at the fingertips of the patients, care-takers and health professionals. It is very important that both valid and accurate health-related information is provided in a cost effective manner to those seeking it.

\section{Conclusions}

The lack of specificity and validity of the app content has a risk of potentially endangering patient safety. Therefore, there is a need to set up regulatory guidelines to improve the quality 
and validity of information disseminated by the smart phone applications. Also, encouraging the involvement of health-care agencies in developing apps aimed at healthcare professionals and general audience would ensure that valid and relevant information reaches the consumers.

\section{References}

1. http://www.go-gulf.com/blog/smartphone/. Accessed on January 2, 2014.

2. http://techcrunch.com/2013/06/10/apples-app-store-hits50-billion-downloads-paid-out-10-billion-to-developers/. Accessed on January 2, 2014.

3. Senior K. Smart phones: new clinical tools in oncology? The Lancet Oncology 2011;12:429-430.

4. Oehler RL, Smith K, Toney JF. Infectious diseases resources for the iPhone. Clinical infectious diseases 2010;50:1268-1274.

5. Hawkes CP, Walsh BH, Ryan CA, Dempsey EM. Smartphone technology enhances newborn intubation knowledge and performance amongst paediatric trainees. Resuscitation 2013;84: 223-226.

6. Rao A, Hou P, Golnik T, Flaherty J, Vu S. Evolution of data management tools for managing self-monitoring of blood glucose results: a survey of iPhone applications. Journal of diabetes science and technology 2010;4:949-957.

7. Rosser BA, Eccleston C. Smartphone applications for pain management. J Telemed Telecare 2011;17:308-312.

8. Robson Y, Blackford S, Roberts D. Caution in melanoma risk analysis with smartphoneapplicationtechnology. Br J Dermatol 2012;167(3):703-704.

9. Kumar S, Wang EH, Pokabla MJ, Noecker RJ. Teleophthalmology assessment of diabetic retinopathy fundus images: smartphone versus standard office computer workstation. Telemedi- cine journal and e-health 2012;18:158-162.

10. Bhosai SJ, Amza A, Beido N, Bailey RL, Keenan JD, Gaynor $\mathrm{BD}$, et al. Application of smartphone cameras for detecting clinically active trachoma. Br J Ophtahlmol 2012; 96:1350-1351.

11. Ambarish P, Sayeedul H, Divyanshu D, Sasmit S. Smartphone apps as a source of cancer information: changing trends in health information-seeking behavior. Journal of Cancer Educ 2013;28:138-142.

12. Kubben PL. Neurosurgical apps for iPhone, iPod Touch, iPad and Android. Surgical Neurology International 2010;1:89.

13. Franko OI. Smartphone apps for orthopaedic surgeons. Clin Orthop 2011;469:2042-2048.

14. Boulos MN, Wheeler S, Tavares C, Jones R. How smart- phones are changing the face of mobile and participatory health- care: an overview, with example from eCAALYX. Biomed Eng Online 2011;10:24.

15. Mosa AS, Yoo I, Sheets L. A systematic review of health- care applications for smartphones. BMC Medical Informatics and Decision Making 2012;12:67.

16. Nam HS, Park E, Heo JH. Facilitating stroke management using modern information technology. J Stroke 2013;15:135-143.

17. Hamilton AD, Brady RR. Medical professional involvement in smartphone Apps in dermatology. Br J Dermatol 2012;167: 220-221.

18. Miller SM, Beattie MM, Butt AA. Personal digital assistant infectious diseases applications for health care professionals. Clin Infect Dis 2003;36:1018-1029.

19. Barrons R. Evaluation of personal digital assistant software for drug interactions. American journal of health-system pharmacy 2004;61:380-385.

20. Franko OI, Tirrell TF. Smartphone app use among medical providers in ACGME training programs. J Med Syst 2012;36: 3135-3139. 